international collaboration, quite apart from the influence of the Trusteeship Council of the United Nations, and, on the other, because a number of studies of special aspects of the problems of particular areas require consideration against that general background; many have their own contribution to make to the solution of the general problem or of specific problems in other areas. A comprehensive perspective is important in appraising the significance of some of the recent changes and moves in government, such as the appointment of Lord Listowel as Minister of State for the Colonies, and Mr. H. A. Marquand's mission to Africa to discuss general trade developments with the Union of South Africa and Southern Rhodesia, and other developments in regional organisation outlined in this survey. The appointment to West Africa of a resident Minister of Cabinet rank has, for example, been perpetuated in the formation of a West African Council of the Governors of the four colonies, with its permanent secretariat, and the Conference on West Indian Federation in Jamaica last September over which Mr. Creech Jones presided, are no less notable as evidence of Britain's readiness to place her unrivalled political experience at the disposal of the Colonial peoples in their progress to self-government.

Such steps indicate how fully the Government appreciates that the changed needs of the time call for an increasing devolution of authority, as well as for the closer integration of government on democratic lines. Moreover, the whole range of government has to be extended so that it may become the instrument of economic and social as well as of political development. Sir Stafford Cripps told the Governors' Conference in November that we are to increase out of all recognition the tempo of African development. Accordingly, just when it is important that new developments of democratic institutions should be firmly based and suited to the capacity of the peoples concerned, it has become imperative that the farreaching changes involved in the relations of governors and governed should be carried through as expeditiously as possible. Any undue time-lag between new legislative and administrative conceptions in Britain and their application to Colonial policy may, indeed, become a positive danger.

\section{NUCLEAR PHYSICS IN PHOTOGRAPHS}

\section{Nuclear Physics in Photographs}

Tracks of Charged Particles in Photographic Emulsions. By C. F. Powell and G. P. S. Occhialini. Pp. ix +124 (50 plates). (Oxford : Clarendon Press ; London: Oxford University Press, 1947.) 18s. net.

7 HE epoch-making discoveries in the field of nuclear physics during the past thirty years have been predominantly due to the development and use of methods of detection of single fast-moving nuclei and electrons. In the experiments of Lord Rutherford upon the scattering of $\alpha$-particles which established the concept of the nuclear atom, in the discovery of the neutron and of artificial transmutation, and in the more recent investigations upon cosmic rays leading to the discovery of the positron and the meson, the part played by the detectors of single charged particles and quanta has been universal and indispensable. It is, therefore, very surprising to reflect that practically all this work has been done with only four basic techniques: the scintillation screen, the Geiger counter, the ionization chamber plus amplifier and the expansion chamber.

For a long time the possibility of direct recording of the tracks of ionizing particles in photographic emulsions has been recognized, but until the immediate pre-war years comparatively few serious experiments had been made by this technique owing to its limitations and insensitivity. During the past ten years, however, Dr. C. F. Powell and his collaborators at the University of Bristol have taken a leading part in the application of this method to a wide range of nuclear investigations, and, with important improvements in the production of more suitable emulsions by Messrs. Ilford, this technique now ranks in power and efficiency with the counter and expansion chamber. The publication of a book by these authors, illustrating so clearly the present potentialities and limitations of the method in expert hands, is, therefore, noteworthy and welcome.

The volume under notice is not, however, a detailed account either of the techniques of preparation and processing of the emulsions or of the experimental arrangements for exposure and measurement of the plates. It is rather, as implied by the title, an album of fifty beautiful photomicrographs illustrating a great variety of nuclear processes. In the brief space of seventy pages of text, the authors make a praiseworthy effort not only to explain the particular phenomena recorded in the photographs, but also to give an elementary account of atomic and nuclear structure and of the basic phenomena of nuclear physics and cosmic rays. It is only natural that such a limited text will confine the educational value, in a formal sense, to students and school teachers, and even for these the absence of phenomena concerning electrons, which are not recorded by this technique, causes a grave lack of generality and balance. How. ever, such criticism is perhaps unreasonable. The avowed purpose of the authors is to present nuclear phenomena in "the robust form and vivid colouring of physical illustrations" which has greater appeal to many minds than purely mathematical expressions. This volume will, I think, be best appreciated by those who can travel, in imagination, with the meson along the tortuous path in the photograph and wonder at the events transpiring at its brief halting point.

Despite the textual limitations, therefore, the authors are to be congratulated on having produced a volume which every experimental nuclear physicist will wish to possess, together with the "Atlas typischer Nebelkammerbilder", by Gentner, MaierLeibnitz and Bothe, which plays a similar part in relation to work which has been done with the expansion chamber. These two volumes have a beauty both of subject-matter and of artistry of reproduction comparable in every way with that of the illustrated books which are so common in the realm of the fine arts. Scientific workers can use them to refute the narrow dogma that "Science deals with facts and Arts with values", which is frequently advanced by their classical friends. We should, indeed, do well to persuade these latter to add these volumes to their own libraries.
P. I. DEE 